tioners in the process (namely, the "wisdom of the crowd") will science return to its significant role of charting the path for the field. If not, academia will be left behind and lose its standing as the shining beacon of the quest for the truth.

\title{
References
}

Buckingham, M., \& Goodall, A. (2015). Reinventing performance management. Harvard Business Review, 93(4), 40-50.

Goler, L. (2015). What Facebook knows about engaging millennial employees. Harvard Business Review, 93( December). Retrieved from https://hbr.org/2015/12/what-facebook-knowsabout-engaging-millennial-employees

Goler, L., Gale, J., \& Grant, A. (2016). Let's not kill performance evaluations yet. Harvard Business Review, 94(11), 90-94.

Grand, J. A., Rogelberg, S. G., Allen, T. D., Landis, R. S., Reynolds, D. H., Scott, J. C., ... Truxillo, D. M. (2017). A systems-based approach to fostering robust science in industrial-organizational psychology. Industrial and Organizational Psychology: Perspectives on Science and Practice, 11(1), $4-42$.

McClelland, D. C. (1965). Toward a theory of motive acquisition. American Psychologist, 20(5), 321333.

Rotolo, C.T., Church, A. H., Adler, S., Smither, J.W., Colquitt, A., Shull, A.C., ... Foster, G. (2018). Putting an end to bad talent management: A call to action for the field of I-O psychology. Industrial and Organizational Psychology: Perspectives on Science and Practice, 11(2), 176-219.

Rowland, D. (2016, October 14). Why leadership development isn't developing leaders. Harvard Business Review. Retrieved from https://hbr.org/2016/10/why-leadership-developmentisnt-developing-leaders?referral=03758\&cm_vc=rr_item_page.top_right

\section{Being Competitive in the Talent Management Space}

\author{
Benjamin Schneider \\ University of Maryland (Emeritus)
}

I have three issues I would like to add to Rotolo et al.'s (2018) arguments for research foci and with which academics must be concerned as we move forward. We must pay attention to all of what Rotolo et al. said plus at least my three additions if we are to compete with other fields playing in the talent management (TM) space. First, I will argue we have become overly concerned in our refereed outlets with theory to the detriment of validity against important organizational outcomes. Second, I will note that industrial and organizational (I-O) psychology has become fixated on individuals and their

Benjamin Schneider, University of Maryland (Emeritus).

Correspondence concerning this article should be addressed to Benjamin Schneider, 1001 Genter St., Suite 2C, La Jolla, CA 92037. E-mail: benj262@outlook.com 
differences to the almost literal exclusion of research on the psychology of organizational phenomena. Third, I will present an argument for research on reciprocal relationships-on organizations as real systems - in an attempt to counter the left-to-right thinking in all of our research models.

\section{On Loving Theory}

I agree with Rotolo et al. (2018)that academic researchers have become enamored of minutiae but, perhaps more dangerously, they have become enamored of theory. Journal editors and reviewers now desire such heavy theoretical introductions to a research article as to drive out the importance of interesting findings-and, of course, drive out publication by those in practice who study interesting phenomena! I have personally experienced this emphasis on theory with my recent research efforts-great data on interesting questions but not supported by 15 pages of theory. Why does one need 15 pages of theory to ask and answer the following question: Do aggregate personality data in organizations correlate with important organizational outcomes? Individual personality data correlate with individual performance, so perhaps aggregate personality data would also? It took Dave Bartram and me 3 years to find an outlet for such research, all the time having the data that it is true-aggregate personality and the variance in aggregate personality across organizations predict financial consequences-and we had to have copious theoretical defense for it (Schneider \& Bartram, 2017). When I first began in the field of I-O psychology, Personnel Psychology had a section called Validity Information Exchange. Why do we not have a section in our journal(s) called something like Interesting Evidence Exchange, in which the measure used is presented with relevant results?

I am not alone in this observation that theory dominates interesting findings. For example, Hambrick (2007) did a wonderful job of showing how theory may be too much of a good thing for research in management, and I assume the statistics he gathered to make his case would apply equally well to the journals that dominate I-O psychology: Journal of Applied Psychology and Personnel Psychology. We seem in I-O psychology (and management research) to have overenthusiastically adopted the famous Lewinian dictum that there is nothing as practical as good theory. For an applied science like I-O psychology, we need good data on outcomes of concern to organizations and good data on outcomes about which management should be concerned. Here is how Hambrick (2007) summarized his piece:

I suspect that many members of our field, including those in leadership positions, believe that our hyper commitment to theory-and particularly the requirement that every article must contribute to theory-is somehow on the side of the angels. They may believe that this is a hallmark of a serious field. They may believe that theory is good and that the "mere" description 
of phenomena and generation of facts are bad. Worse yet, they may have given no thought to

these matters, accepting our field's zeal about theory as simply part of the cosmos. (p. 1351)

I agree, and things have gotten even worse since 2007. This is not a good path to making us relevant to the world of TM, especially when it is combined with statistical minutiae.

\section{Organizations as the Needed Level of Analysis}

My second issue concerns the levels of analysis. I-O psychology has been forever limited in its influence by the success we had early on with personnel selection validity and the study of individuals and their differences. We are still locked into Morris Viteles's (1932, p. 29) definition of industrial psychology: "Industrial psychology is based on a study of individual differences-of human variability" (italics in the original). This successful focus on individual differences resulted in us doing early research at the individual level of analysis, even when we were studying, for example, organizational climate (Ehrhart, Schneider, \& Macey, 2014). I have spent most of my career attempting to drive research on psychological constructs to the organizational level of analysis. Yet, even today, if one explores the titles of articles in JAP or Personnel Psychology —or Organizational Behavior and Human Decision Processes-one is hard pressed to find research by I-O psychology academics at the organizational level of analysis. This is somewhat paradoxical, given the appropriate success of the Klein and Kozlowski (2000) required reading on levels issues.

Think about the following: As interested and successful as we have been in personnel selection, there is precious little evidence that organizations using validated selection procedures are more successful compared to organizations not using such selection procedures (see Oh, Kim, \& Van Iddekinge [2015] and Schneider \& Bartram [2017] for exceptions). But, you say, there is all that utility analysis to show that a company will benefit from using validated procedures. Yes, a company will benefit, but will that same company be more successful than other companies not using such procedures? Similarly, with regard to employee engagement: Are companies that have higher aggregate employee engagement scores competitively more successful than those with lower aggregate engagement scores?

I agree with Rotolo et al. (2018) that engagement is a muddy construct as assessed in practice where most of the measures used get at organizational engagement (commitment) and not engagement in work (Schneider, Yost, Kropp, Kind, \& Lam, 2017). My major point with regard to levels issues also is a critique of our journals. So, with regard to my own project on this question of organizational levels of work engagement, the article was rejected at one of our finer I-O psychology outlets because "work engagement is not an 
organizational construct." How can a meaningful psychological construct not be a meaningful aggregate construct? Have reviewers and editors not read what McClelland (1961) did with the individual need for achievement at the country level of analysis? Have reviewers and editors not read what the climate researchers have shown about how aggregate perceptions of psychological climate are significantly related to customer satisfaction and other relevant organizational outcomes (Schneider, González-Romá, Ostroff, \& West, 2017)?

In any case, for interested readers, two recent studies of aggregate engagement across companies indicate that work engagement is indeed a viable aggregate construct with reliable predictive validity across both financial and customer outcomes (Barrick, Thurgood, Smith, \& Courtright, 2015; Schneider, Yost, et al., 2017). These articles have practical usefulness as well because of the financial outcomes used as criteria and also because they reveal the drivers of engagement in the form of policies and practices over which organizations have some control. As I-O types, we have this understandable but not validated implicit belief that competitive organizational consequences follow from the studies we do at the individual level of analysis-but we had best be able to show evidence that the belief is valid and provide concrete data on what organizations can do to make improvements, and our journal editors and reviewers have to be ready to think about organizational performance and not just individual performance.

\section{On Organizations as Reciprocating Systems}

My third issue concerns the dominance of left-to-right thinking in our field. Engagement causes performance; climate causes customer satisfaction; satisfaction causes performance; leadership causes performance; and so forth. Left to right thinking ignores the fact that organizations are systems of interacting and reciprocal elements, and it leads to causal modeling as if the world works in a left-to-right mode. Well it does not work that way. For example, in several projects my colleagues and I have shown that (a) service climate and customer satisfaction are in reciprocal relationships across bank branches (Schneider, White, \& Paul, 1998) and (b) job satisfaction and organizational performance are in reciprocal relationships over an 8-year time frame (Schneider, Hanges, Smith, \& Salvaggio, 2003). As another example, consider the excellent study by Xanthopoulou, Bakker, Demorouti, and Schaufeli (2009), who showed that job resources and work engagement are in reciprocal relationships over time. So, employees feel more positive about the service climate in which they work when customers they deal with are more satisfied, employees experience superior job satisfaction in financially successful firms, and employees experience high levels of resources at work when they are more engaged. As you read this, you say to yourself 
something like: So what else is new; that is the way the world works. Well, if the world works that way, why do all of our boxes and arrows run from left to right with only an occasional feedback loop indicating the possibility of a reciprocal relationship?

From a conceptual standpoint, reciprocal thinking yields the conclusion, as Xanthopoulou et al. (2009, p. 235) put it: "These findings support the assumption of Conservation of Resources theory that various types of resources and well-being evolve into a cycle that determines employees' successful adaptation to their work environments." In other words, the context in which people work certainly can yield a wide variety of positive and negative experiences, and in turn those experiences determine the way the context is viewed. If those experiences, in turn, are reflected in outcomes important to the organization, then it is changes in context that must be made to achieve the outcomes desired. That is nothing new but, and here is the important point: When the outcomes that are desired are indeed achieved, then the context will be seen more positively, the experiences people have there will be more positive, and the cycle will be self-reinforcing over time. Thus, there is no doubt that direct manipulation of the outcomes is not possible (you cannot just go out and find satisfied customers to improve service climate, for example), but interventions can be made to achieve a more positive climate/higher job satisfaction/engagement, and this will get the cycle going and that is what is necessary in a real system. It is of course necessary to not only have frameworks that have reciprocity built into them but then research must be carried out over multiple periods of time to establish whether and how the reciprocity works.

\section{Summary}

The Rotolo et al. (2018) focal article is a stimulus for I-O researchers to get busy and produce research that pushes the field forward so that we earn the right to be prominent players in the future of TM. I am convinced the best way to do that is to do research that is (a) driven by important outcomes and not just theory, (b) that is done at the organizational and not only the individual level of analysis, and (c) that is framed with and documents the important reciprocal relationships that create the cycles of success that can sustain organizations over time.

\section{References}

Barrick, M. R., Thurgood, G. R., Smith, T. A., \& Courtright, S. M. (2015). Collective organizational engagement: Linking motivational antecedents, strategic implementation, and firm performance. Academy of Management Journal, 58, 111-135. https://dx.doi.org/10.5465/amj.2013.0227

Ehrhart, M. G., Schneider, B., \& Macey, W. H. (2014). Organizational climate and culture: An introduction to theory, research and practice. New York, NY: Routledge. 
Hambrick, D. C. (2007). The field of management's devotion to theory: Too much of a good thing? Academy of Management Journal, 50, 1346-1352. https://dx.doi.org/10.5465/AMJ.2007. 28166119

Klein, K. J., \& Kozlowski, S. W. J. (Eds.) (2000). Multilevel theory, research, and methods in organizations: Foundations, extensions, and new directions. San Francisco, CA: Jossey-Bass.

McClelland, D. C. (1961). The achieving society. New York, NY: Van Nostrand.

Oh, I., Kim, S., \& Van Iddekinge, C. H. (2015). Taking it to another level: Do personality-based human capital resources matter to firm performance? Journal of Applied Psychology, 100, 935-947. http: //dx.doi.org/10.1037/a0039052

Rotolo, C. T., Church, A. H., Adler, S., Smither, J. W., Colquitt, A., Shull, A. C., ... Foster, G. (2018). Putting an end to bad talent management: A call to action for the field of I-O psychology. Industrial and Organizational Psychology: Perspectives on Science and Practice, 11(2), 176-219.

Schneider, B., \& Bartram, D. (2017). Aggregate personality and organizational competitive advantage. Journal of Occupational and Organizational Psychology, 90(4), 461-480. http://dx.doi.org/ 10.1111/joop.12180

Schneider, B., González-Romá, V., Ostroff, C., \& West, M. (2017). Organizational climate and culture: Reflections on the history of the constructs in Journal of Applied Psychology. Journal of Applied Psychology, 102, 468-482. http://dx.doi.org/10-1037/apl0000090

Schneider, B., Hanges, P. J., Smith, D. B., \& Salvaggio, A. N. (2003). Which comes first: Employee attitudes or organizational financial and market performance? Journal of Applied Psychology, 88, 836-851. http://dx.doi.org/10.1037/0021-9010.88.5.836

Schneider, B., White, S. S., \& Paul, M. C. (1998). Linking service climate and customer perceptions of service quality: Test of a causal model. Journal of Applied Psychology, 83, 150-163. http://dx.doi. org/10.1037/0021-9010.83.2.150

Schneider, B., Yost, A. B., Kropp, A., Kind, C., \& Lam, H. (2017). Workforce engagement: What it is, what drives it, and why it matters for organizational performance. Journal of Organizational Behavior. http://dx.doi.org/10.1002/job.2244

Viteles, M. (1932). Industrial psychology. New York, NY: Norton.

Xanthopoulou, D., Bakker, A. B., Demerouti, E., \& Schaufeli, W. B. (2009). Reciprocal relationships between job resources, personal resources, and work engagement. Journal of Vocational Behavior, 74, 235-244. https://doi.org/10.1016/j.jvb.2008.11.003.

\section{What if Any Science Will Do?}

\section{Fred Delmhorst}

Time Warner, Inc.

Rotolo et al. (2018) identify a number of reasons why the field of industrial and organizational (I-O) psychology is losing relevancy, including a lack of focus on frontier topics, which may be most relevant to talent management practitioners. As someone who subscribes to the benefits of the scientistpractitioner approach to talent management, there is nothing I hold more

Fred Delmhorst, Time Warner, Inc.

Correspondence concerning this article should be addressed to Fred Delmhorst, Time Warner, Inc., One Time Warner Center, New York, NY 10019. E-mail: fred.delmhorst@gmail.com 